\title{
Digital Cyclical Ecological Regional Self-Sufficient Economy
}

\author{
Evgeniy Bryndin \\ Research Center "Natural Informatics", Novosibirsk, Russia
}

\section{Email address:}

bryndin15@yandex.ru

\section{To cite this article:}

Evgeniy Bryndin. Digital Cyclical Ecological Regional Self-Sufficient Economy. European Business \& Management. Vol. 6, No. 3, 2020, pp. 42-48. doi: 10.11648/j.ebm.20200603.11

Received: May 26, 2020; Accepted: June 5, 2020; Published: June 28, 2020

\begin{abstract}
The economy is sphere of public work and the set of relations that form in the system of production, distribution, exchange and consumption. The paper examines the digital, cyclical, environmental and regional aspects of a cyclical digital environmental regional economy. The digital direction of the economy uses digital twins and robots as assistants to improve its quality, productivity and efficiency. The cyclical economy uses savings and profits to boost its competition and development. The environmental direction of the economy maintains the viability of the environment. The regional economy increases diversification and capacity of local production and preserves the environment in its territory regardless of the type of economic activity. Cyclical aspects of the economy of self-sufficiency mainly concern the financial round-up, and the closed reproduction cycle. Business models of cyclic reproduction realize its economic self-sufficiency. At present, Russia, China, the United States and EU integration education have achieved the optimal level of national economic self-sufficiency. Russia, the United States, and the EU have the necessary financial and human resources. At the same time, China, with excessive human resources, is pursuing a policy of expansion into developing and underdeveloped countries. The main reason for countries to abandon autarky policies in favor of globalization of research activities is the decline in profit levels. The reason for this situation lies in the availability of cheap labour and favourable economic conditions, and production in countries is therefore cheaper. The reason for globalization and the international division of labour lies in maximizing profits, and autarks in maximizing national production, i.e. self-sufficiency. The unity of the Autarky State must be ensured by the existence of economic, historical, cultural ties, as well as by national equilibrium.
\end{abstract}

Keywords: Digital Sector, Cyclical Aspects, Ecological Modernization, Regional Features of Economics

\section{Introduction}

In 1995, American computer scientist Nicholas Negroponte (University of Massachusetts) introduced the term "digital economy." The digital economy is a digitalbased economic activity. According to a 2017 study, Norway, Sweden, Switzerland, Denmark, Finland, Singapore, South Korea, Great Britain, Hong Kong, and the United States TOP-10 among the countries with the most advanced digital economy. Singapore, Great Britain, New Zealand, the UAE, Estonia, Hong Kong, Japan and Israel were characterized by high levels and rapid rates of digital development. In 2019, the size of the digital economy is estimated to be between 4.5 and $15.5 \%$ of world GDP. The United States and China accounted for almost $40 \%$ of the value added generated in the global information and communications technology (ICT) sector. Rapidly spreading digital technologies are transforming many economic and social activities. They help to develop cyclical economy.

The cyclical economy was first talked about in 1970. The authorship of the approach and the titles are attributed to economists John Lyle and Walter Steiner. The Swedish nonprofit organization The Natural Step, which promotes the ideas of sustainable development and the European Commission, has developed the idea of a new economic paradigm [1]. According to cyclical principles, it is proposed to immediately create a cycle of materials and energy of all types of production and consumption. When the manufacturer decides to release the goods, it thinks in advance about the cycle of their ecological existence in the economic system. The cyclical economy today has two main drivers - large companies and governments. The activities of 
large transnational corporations cover the entire production chain from the supply of materials to the sale of goods, and it is easier and more profitable for them to implement cyclic projects. State institutions also contribute to the advancement of the cyclical economy. They create a favorable tax, legislative and institutional environment for the development of new business models, to support initiatives in cyclical production and management. The Closed Cycle Economy Promotion Act was passed in China, with Scotland issuing its cyclical economy development plan. The European Commission has issued documents that should increase the planned indicators of waste processing and prohibit the disposal of materials that can be put back into production.

The entry of regions into the international arena as direct actors represents the most important trend of the XXI century not only for developed countries, but also for Russia. The region is becoming almost a key concept of a new reality. Russia is characterized by a steady increase in interest in regional issues. In our country, the theme of regional development has become one of the priority themes of economic development.

\section{Digital Sector of Economy}

The digital economy itself, without the real and raw materials sectors, without production, which turns raw materials into products, without agriculture and without transport, delivering raw materials to the plant, products to the warehouse and goods from the warehouse to the store or to you to the house - cannot exist. That is, the digital economy is not a holistic economy, but a sector consisting of digital technologies and services (including services of choice and order of real goods). Therefore, it is more correct to say not the digital economy, but the digital sector of the economy. The digital sector of the economy serves the industrial, financial and other sectors of the economy.

The digital economy provides a much faster, better and more convenient information, educational, scientific, medical list of services. The digital economy of many countries of the world is in a stage of rapid development. There are robots consultants, lawyers. In Japan, robots work in hospitals. They are worn by the patient's hands covered in soft material from place to place. Kiva Systems produces transport robots. They receive a command from the operator to deliver the right item in the warehouse, find it and deliver it to the packer.

Modern information and computer technologies establish links between companies, banks, government and the population, removing long chains of intermediaries and accelerating the conduct of various transactions and transactions (sales, credit, rent, payment of taxes, fines, contributions, other payments and settlements).

The Boston Consulting Group predicts that the digital economy could reach $\$ 2035$ trillion by 16 . According to the consulting company Accenture, the use of digital technologies should add 1.36 trillion US dollars in 2020, or $2.3 \%$ of GDP in the total GDP of dozens of the world's leading economies. The GDP of developed countries will grow by $1.8 \%$ at the expense of the "digital economy" and that of developing countries by $3.4 \%$.

The digital model of the economy will provide "digital dividends" to society in the form of higher productivity, increased competitiveness of companies, reduction of production costs, reduction of crises through accelerated sale of goods and services, growth of high-tech employment of the population, more complete satisfaction of human needs and even weakening or complete overcoming of social polarization of society.

The development of the digital economy is based on mass and quality data collection and analysis and formalization for digitization. Whoever offers fundamentally new - "digital" ways to meet new and old needs, simply has to create and learn new principles of communication with clients and work in markets. It should visualize needs and products, include consumers in the digital economy, provide constant and convenient support for them. It needs a digital interaction management system that makes it possible in practice to predict, plan, organize, execute, monitor and coordinate all activities for the active use of data to meet the necessary needs of mankind.

The digital platform is a new, only characteristic business model for the digital economy, the essence of which is to provide businesses and the population with a specific service to coordinate the activities of various market participants. The platform provides participants with a number of amenities, automatically generates trust ratings between them, and most importantly, allows sellers and buyers of goods/services to quickly find each other, quickly make a deal and make calculations. The operation of platforms accelerates and reduces the cost of selling goods, eliminates unnecessary intermediaries, dramatically increases the efficiency of markets and productivity. At the same time, many platforms can serve participants of transactions without any geographical restrictions, almost all over the planet. The platform concept was developed and implemented mainly in the segment of trade and logistics. Examples of digital platforms are Uber, Airbnb, Amazon, Alibaba and others. Today, different digital platforms are being combined into interconnected, data-based "ecosystems" spanning a vast number of different markets and smart businesses.

All links of smart enterprises are extremely automated by digital twins with artificial intelligence and robotic. Manufacturing processes and smart enterprise lines can be quickly updated and rebuilt. At all stages of the product lifecycle, smart enterprise functions work as a single, interconnected entity, controlled by online feedback flows. The entire product lifecycle (PLM), including integration with logistics, service centers, and feedback, becomes a management object.

Today, the digital economy with artificial intelligence is named one of the priorities of Russia's scientific and technological development strategy. Training of personnel in the high-tech field, development of high-tech industry and intellectual consistent digitalization of the Russian regional economy will become a platform for qualitative change of its 
structure and long-term opportunities [2-15].

\section{Cyclic Aspects of Economy}

The cyclical aspects of the economy mainly relate to the financial round-up, and the closed production cycle. The challenge of a cyclical economy is to use renewable resources as widely as possible and ideally to switch to waste-free production. Repeated use of the same material as raw materials will help to minimize economic damage to the environment, analysts of the Organization for Economic Cooperation and Development (OECD) - a club of 36 most developed countries of the world believe. In their study "Business Models of the Cyclical Economy," they looked at the major challenges and opportunities of the cyclical economy and how governments can contribute to its implementation.

The closed-loop economy, also called cyclic or circular, is based on the principle of resource reuse - the producer must understand at the stage of commodity design how it will be recycled. A product that is created within a cyclical economy should serve a long time, and the consumer should be able not to purchase, but to rent.

Cyclical business models change the direction of products and materials throughout the economy, which helps to reduce the negative impact of mining, use and disposal of these materials for nature. It is not only about improving a specific production cycle or factory, but in general about changing the production and consumption process. For example, it is not easy to manage natural resources more effectively, not to use them at all. Five main directions of such business models can be distinguished.

1. The model of cyclic supply - replacement of traditional (primary) sources of raw materials with renewable or biological materials, secondary.

2. Recycling model - recycling waste and subsequent use.

3. The model of life extension - slows down the turnover of products in the economy, thus reducing the rate of generation of new wastes.

4. The shering model is the sharing of a single product by different consumers, which reduces the demand for new products.

5. Service models are built around the provision of services rather than the sale of products, stimulating the development of environmentally friendly products and responsible consumption.

Many companies combine a business model. For example, an enterprise can produce certain products, process them and at the same time provide some services within the green economy. Also, business models do not exist in isolation - if one company chooses a specific direction for itself, its partners can choose a related business model. By closing the resource chain and slowing the movement of products within the economy, cyclic business models reduce the negative effect of economic activities on the environment. For example, recycling, rather than non-renewable resources, can reduce greenhouse gas emissions by up to $90 \%$, depending on the industry. Restoring fully used products will reduce waste generation by up to $80 \%$.

The use of some models is growing at a faster rate than the market and this is largely due to the development of technologies. In order to expand the market share of proven cyclical models, integrated solutions at the government level will be needed. Ultimately, the transition to a visibly more resource-efficient economy, in which the environmental damage associated with production and consumption is markedly lower than the current one, will require deep penetration of these cyclical business models. Government policies can play an important role in overcoming obstacles to the competitiveness of these models. For example, to ensure that the environmental costs of production and consumption of the product are fully reflected.

A cyclical economy presupposes a sustainable system of financial cyclical cycles from investment to accumulation based on numerical indicators. From a socio-economic point of view, this means achieving the goal is based on parameters that require dynamic quantification: price, tariff, profitability, costs, liabilities, assets, returns, losses, dividend, rents, stock index, book value, wages, costs, and others. Dynamic quantitative assessment of socio-economic parameters will ensure the necessary measure, number and weight, as well as stability of the system of financial cyclic circulations from reinvestment to accumulation.

Savings for reinvestment (HR) is the profit left at the disposal of the enterprise (retained earnings, as well as funds and reserves created by profit):

$$
\mathrm{RS}=\mathrm{NP}-\mathrm{D} \text {, }
$$

where, NP - net profit, D - dividends.

The formula for calculating the money reinvestment ratio is:

$$
\mathrm{KR}=(\mathrm{IFA}+\mathrm{IWC}) /(\mathrm{NP}+\mathrm{BR}-\mathrm{NCS}-\mathrm{D}) * 100 \% \text {, }
$$

where KR - money reinvestment ratio, \%;

IFA - increase of fixed assets;

IWC - increase of working capital;

NP - net profit;

$\mathrm{BR}$ - non-cash expenses;

NCS - non-cash sales;

$\mathrm{D}$ - dividends.

The cash flow reinvestment ratio shows that cash flows can cover the need to update the fixed and working capital used in the company's current operations. The money reinvestment ratio is useful when it is necessary to determine the amount of cash flows that a company regularly invests in environmental renewal of production.

In a cyclical economy, the decision on the size and rate of accumulation is taken and implemented at the enterprise level to facilitate reinvestment of savings in enterprises. The increase in accumulation is due to technical prerequisites the possibility of mastering the world achievements of scientific and technological progress, the level of development and the structure of the national economy. 
The financial turnover of the cyclical economy through reinvestment of its savings allows carry out ecological modernization, diversification and development of various industries.

\section{Environmental Modernization of Production and Consumption}

In a rapidly changing world, the environmental characteristics of production become one of the main conditions for the success of the enterprise. Today the development of enterprises is impossible without ecological modernization of production, transition to the best available technologies. It is a global trend. The accumulated landfills should be a source of resources and energy for the industrial industry. Special attention should be paid to the creation of environmental technologies for the processing of garbage and waste. Consumption should not be linked to the growing production of waste from landfills or incinerators. $80 \%$ of goods end up in landfill for the first six months of their existence. The transition to environmental technologies for the processing of garbage and waste, to environmental production and to a cyclical economy with reinvestment of savings should be the main task of all States. These activities will preserve the environment, ensure the cleanliness of air, water and food and get rid of waste and garbage [18].

Cyclical business models change the direction of movement of products and materials throughout the economy, which helps to reduce the negative impact of extraction, use and disposal of these materials for nature [19]. It is not only about improving a specific production cycle or factory, but in general about changing the production and consumption process. For example, it is not easy to manage natural resources more effectively, not to use them at all. Recycling can reduce greenhouse gas emissions by up to $90 \%$, depending on the industry. Restoring fully used products will reduce waste generation by up to $80 \%$. The cyclical economy with reinvestment of savings in ecological modernization of various industries is the driver of clean cities and agglomerations and public health. Ecological modernization of production facilities is carried out according to closed technological cycles.

A closed process cycle is a production process that does not produce production waste. This is possible if the waste of one production process is at the same time the raw material for another, and the whole amount of raw materials will be processed into final products.

Currently, there are no $100 \%$ closed process cycles, as not all waste can be used for by-product production. At the present stage it is possible to talk only about low-waste production, at which the degree of closure of the technological cycle approaches $100 \%$. Most often, a closed cycle of production is achieved in agriculture. This is due to the possibility to bring the production process in this industry closer to the processes of natural ecosystems functioning. Biomass generated in the crop sector is partly used in the livestock sector, and organic livestock waste, such as manure, is a fertilizer for growing crops.

In modern low-waste production it is possible to close only certain technological stages, for example water supply. Such systems are referred to as return water systems, such as return water systems. An example of the implementation of such technologies is the pulp and paper industry, which produces a large amount of industrial waste water contaminated with the most dangerous chemical compounds. Most of these plants have now implemented waste water treatment systems to bring the quality of wastewater to a level where it can be reused in pulp washing. Thus, the production effluent of the pulp and paper mill no longer enters the environment, and water from natural water bodies is only taken to compensate for the evaporation losses.

Low-waste technologies are also actively introduced at chemical industry and metallurgy enterprises. There this is due to the emergence of a large number of by-products of the main chemical process. In ore refining plants, sulfur gas formed in the process comes into contact with absorbing liquids of various chemical composition, which allows to obtain mineral fertilizers, for example superphosphate and ammonium sulfate, as well as construction materials. If water is used as the absorbing liquid, it is possible to obtain sulphuric acid, which is widely used as a raw material for many processes. Similar schemes for sending waste as raw material to other processes are used when removing nitrogen compounds from exhaust gases. Nitric acid and valuable nitrogen fertilizers are obtained.

The process of returning production and consumption waste to the production process is called recycling. As a rule, production waste cannot be returned to the same production process in which it was generated, otherwise these materials would not have been waste initially. An example of recycling production waste into the same production cycle may be metallurgical production or glass and paper production, in which the final product, which for some reason has lost its consumer properties, such as scrap glass, paper trimming or non-standard metal blanks, can be recycled in the main process. In most cases, production waste may be a raw material for the production of products of a fundamentally different product group than the products in which the waste was produced. For example, sulfur and nitrogen oxides from metallurgical production can be used in the production of suitable acids and certain groups of mineral fertilizers, but not in metallurgical production.

Waste generated by product consumption is more likely to be recycled. For example, a polyethylene film that has lost its consumer properties can be reused as a raw material for polyethylene production. Empty glass bottles can be returned to glass production. The same can be said about scrap of ferrous and non-ferrous metals, as well as about paper waste, recycling of which is widespread. Recycling is an effective tool for reducing waste quantities and reducing resource consumption. Through recycling, large quantities of valuable materials can be returned to the production cycle, thereby reducing the level of raw material production and reducing 
the rate of depletion of natural resource potential.

Waste-free production is called production, in which all raw materials and even wastes are still converted into finished products. Among other things, the concept of such a process provides for the processing of any product, even after its moral or physical wear. It is a closed cycle that can only be compared to natural environmental systems based on biogeochemical cycles of substances. The creation of wastefree production is a gradual and long process that requires a number of economic, technological, psychological, organizational and other tasks. The following principles of waste-free production are used:

1. cyclicity of material flows - a closed production process, which in a certain way can repeat natural cycles;

2. rational organization is when irreparable resource losses can be minimized through waste recycling;

3. principle of environmental safety.

Waste-free and low-waste technology ensures complete processing of raw materials when using components based on production of new waste-free processes; Production and manufacture of new varieties of products, taking into account the request for recycling; Use and consumption of waste with the final production of commercial products or any useful use thereof without shifting ecological equilibrium; The use of closed water supply systems in industry; production of wastefree complexes.

Waste-free production in Russia is famous for wood processing, today its level is more than $80 \%$. Practically all waste is processed into useful products, namely fuel briquettes and granules. Chips and sawdust are perfectly suitable for heating, as such raw materials are considered cheap enough and have good heat removal. Waste-free wood production is called the highest quality and closed process, as waste from it is minimized, and it can be said, practically absent. In addition to traditional lumber, high-quality furniture shields and furniture can also be produced.

In agriculture, sound manure processing can serve as waste-free production. The starting material is used to fertilize feed crops, which are then fed to the available stock.

Environmental ecology particularly requires the reprocessing of debris and waste into energy and replenished resources. Food waste needs to be separately collected and processed by composting into mineral fertilizers to avoid multiplying infectious diseases and epidemics through landfills, animals and birds.

\section{Features of Russia's Regional Economy}

The peculiarities of Russia's regional development are due to the creation of a new geopolitical space and a fundamentally new model of economic development.

The fundamental basis for the economic development of the regions is the concentration of economic activity in the territories. Development is determined by such factors as availability of natural resources, geographical location, agglomeration effect, human capital assets, institutional environment.

In the existing spatial configuration, the regional economy is characterized by a gap in the rate of economic growth between the various subjects of the Russian Federation. In this regard, the improvement of regional governance mechanisms and the development of innovative regional policy instruments have become vital. Finding optimal options for regional development is an important task that is being addressed according to the specific development context. The analysis of the main trends in regional development has led to the identification of the main mechanisms for spatial development.

An important aspect of regional development is the approach to improving the resettlement system and the priorities for the deployment of productive forces. The use of regional forms of development that ensure the integrated development of territories includes such mechanisms as special economic zones, advanced development territories, regional development zones, territorial clusters and urban agglomerations. It is rational to optimize and justify promising approaches to administrative territorial division, as well as to develop geographically justified state programs taking into account the creation of territories ahead of development and priorities for developing regions of special strategic importance.

At the regional level, the preparation of state programmes for the development of the economy and social sphere should take into account justified proposals by local authorities concerning the allocation of local production, social, transport, customs infrastructure and logistics. This should be based on economic priorities and competitive advantages that exist in municipalities.

Strategies for the socio-economic development of federal districts are of particular importance in the system of strategic regional development. They are designed to coordinate the development of federal, regional and municipal infrastructure, taking into account the territorial distribution of the resource base, the rational interregional division of labour and interregional economic integration [20].

The system of strategic planning of social and economic development of the constituent entities of the Russian Federation, municipalities should have a predictable, favorable environment for planning and implementation of investment projects and business programs. The economic nature of the measures should be reflected in the creation of the most favourable conditions for the development of business in the respective territories in terms of their economic specialization and social modernization. At the same time, the importance of harmonizing social and economic development strategies for all federal districts and coordinating the activities of regional bodies to implement measures to support international economic activities, create a favourable investment climate and attract foreign investments is increasing. 
At the regional level, there is a need to consolidate resources and development mechanisms by diversifying the structure of the economy and employment in regions and cities. It is also important to create and develop importsubstituting and export-oriented high-tech industries. The creation of functionally balanced systems to support exports and attract investment from regional perspective.

Regional policies should also include measures to encourage internal migration of the population in order to consolidate the necessary permanent labour resources in the developing territories through the intensification of industrial activities and the creation of quality social infrastructure.

Training and retraining of personnel to meet the labour needs of regional economies in the territorial and vocational context, taking into account the promising long-term investment plans of large companies and the organization of cooperation with educational institutions, becomes relevant.

A priority area of regional development is the development of a set of measures and tools that provide motivation for the mobilization of domestic resources and the enhancement of the Territories 'own economic potential. Clear regional development priorities have a positive impact on the effectiveness of the measures and instruments introduced.

Multi-level governance involving national, regional and local authorities, as well as stakeholders as experts and research organizations, is also important for effective regional economic development.

Regional economic development programmes should focus on mechanisms to support competitive advantage in the region's contribution to its development dynamics. Indicators and standards should be established in monitoring and evaluating the results of programmes aimed at regional development. Then regional development will indeed be aimed at improving efficiency, taking into account the peculiarities of the regions.

\section{Conclusion}

In addition to scientists, global corporations and world leaders, the progressive public of all countries has become involved in promoting the ideas of the cyclical digital environmental regional economy. So far, we are talking about separate closed processes and an attempt to make the idea the general line of development of the world economy in the future.

Russia's cyclical digital environmental regional economy will be able to sustain economic growth without draining resources. It can provide the necessary human needs without loading the ecosystem with waste and pollutants. Models of cyclic digital environmental regional economy, based on a well-thought-out cycle of waste-free and safe production, are supported by business, entrepreneurs, authorities and the population. They allow to take into account and minimize environmental consequences immediately when creating a product, rather than to fight them after the release of a commodity - ideally creating a system of economic activity that meets the needs of man and is organically integrated into the natural ecosystem [21]. The transition to a cyclical digital environmental regional economy is a necessary way for the economic viable development of the regions and the solution of their environmental, economic, climatic, healthy and other problems.

\section{References}

[1] Green Public Procurement for a Cyclical Economy, Handbook and Good Practices. European Commission 2017. $20 \mathrm{p}$.

[2] Evgeniy Bryndin. Cognitive Robots with Imitative Thinking for Digital Libraries, Banks, Universities and Smart Factories. International Journal of Management and Fuzzy Systems. V. 3, N. 5, 2017, pp 57- 66 .

[3] Evgeniy Bryndin. Development of Artificial Intelligence by Ensembles of Virtual Agents on Technological Platforms. COJ Technical \& Scientific Research. 2 (4). 2020. Pages: 1-8.

[4] Evgeniy Bryndin. Supercomputer BEG with Artificial Intelligence of Optimal Resource Use and Management by Continuous Processing of Large Programs. International Journal of Research in Engineering, Vol. 1, Issue 2, 2019. Pages: 9-14.

[5] Evgeniy Bryndin. Development of sensitivity and active behavior of cognitive robot by means artificial intelligence. International Journal of Robotics Research and Development. VOL - 10, ISSUE - 1; 2020. Pages: 1-11.

[6] Evgeniy Bryndin. Increased Sensitivity and Safety of Cognitive Robot by Development of Professional and Behavioral Skills. Saudi Journal of Engineering and Technology. Volume-5, Issue-5 2020. Pages: 187-196.

[7] Markets and Markets Research - Collaborative Robots Market", $2017 . \quad$ URL: https://www.marketsandmarkets.com/MarketReports/collaborative-robot-market-194541294. html

[8] Robotics Business Review - “The 2017 RBR50 List Names Robotics Industry Leaders, Innovators", 2017 URL: https://www.roboticsbusinessreview.com/download/2017rbr50-list-names-robotics-industry-leaders-innovators/

[9] Cision. "Top Robotics Market by Industrial Robotics, Service Robotics - Global Forecast to 2022”, 2017. URL: https://www.prnewswire.com/news-releases/toproboticsmarket-by-industrial-robotics-service-robotics--global-forecastto-2022-300405291.html

[10] Gizmodo. "Robots Are Already Replacing Human Workers at an Alarming Rate", 2017. URL: https://gizmodo.com/robotsarealready-replacing-human-workers-at-an-alarmi1793718198

[11] Evgeniy Bryndin. Digital technologies of the industry 4.0. / Chepter 10, C. 201-222, Book: Computer Science Advances: Research and Applications. USA: Nova Science Publisher. 2019. 252 pages.

[12] Evgeniy Bryndin. Social Cognitive Smart Robots: Guide, Seller, Lecturer, Vacuum Cleaner, Nurse, Volunteer, Security Guard, Administrator. Communications. Volume 7, Issue 1. 2019. Pages: 6-12. 
[13] Google's Artificial Intelligence Built an AI That Outperforms Any Made by Humans. 2019 https://futur-ism.com/googleartificial-intelligence-built-ai.

[14] Evgeniy Bryndin. Formation of Technological Cognitive Reason with Artificial Intelligence in Virtual Space. Britain International of Exact Sciences Journal, Vol. 2 No. 2, May 2020.

[15] Evgeniy Bryndin. Mainstreaming technological development of industrial production based on artificial intelligence. COJ Technical \& Scientific Research, 2 (3). 2019. Pages: 1-5.

[16] Evgeniy Bryndin. Financial Turnover of Cyclical Economy by Reinvesting in Ecological Production of Its Savings. $J$. Resources and Environmental Economics. Volume 2, №. 1. Singapore: Syncsci Publishing. 2020. Pages: 96-101.

[17] Evgeniy Bryndin. Cyclical Ecological Economy with Reinvesting of Its Savings. Integrative Journal of Conference Proceedings, 2 (2). 2020. P. 1-5.
[18] Evgeniy Bryndin. Development of living floor spaces on the basis of ecological economic and social programs. $J$. Resources and Environmental Economics. V. 1, №. 1.. Singapore: Syncsci Publishing. 2018. P. 1-8.

[19] Evgeniy Bryndin. Mobile Innovative Transformational Ecosystem of Management of Humane Technological Society. Integrative Journal of Conference Proceedings. Volume 1, Issue 3, 2019. Pages: 1-6.

[20] Rubtsov G. G., Litvinenko A. N. Role of interregional cooperation in the system of modern regional economy of the Russian Federation. Scientific and technical sheets SPbSPU. Economic sciences. Volume12, № 1, 2019. Page 97-110.

[21] Katie Houston, Adam Fishwick, Nick Compton. Tvitonomika. Alpina Didzhital. 2014. 200 pages. 